\title{
Development and Evaluation of a Student Pharmacist Clinical Teaching Unit Utilizing Peer-Assisted Learning
}

\author{
Adrienne J Lindblad, Jason M Howorko, Richard P Cashin, Cornelius J Ehlers, and Cheryl E Cox
}

\section{INTRODUCTION}

$\mathrm{T}$ he demand for experiential learning opportunities for

student pharmacists has been increasing in both Canada and the United States. ${ }^{1,2}$ The increasing number and duration of experiential placements in hospitals, combined with a limited number of pharmacist preceptors, may jeopardize the ability to achieve curricular outcomes.

Many institutions use a 1:1 ratio of student pharmacists to preceptors for hospital experiential programs. Anecdotally, this model may build a strong one-to-one relationship between the preceptor and the student, allowing demonstration of the student's contributions. However, it cannot accommodate a large number of students, and the preceptor must spend a substantial amount of time organizing each rotation.

Practitioners and researchers are calling for creative options to deliver experiential education. ${ }^{2}$ Peer-assisted learning employs "people from similar social groupings who are not professional teachers helping each other to learn and to learn themselves by teaching". ${ }^{3}$ Peer-assisted learning and the use of higher student-to-preceptor ratios has been advocated in a number of health care professional programs, but this model has not been investigated for experiential training of pharmacists. ${ }^{4-6}$

This paper describes the implementation and evaluation of a clinical teaching unit for experiential education of student pharmacists, whereby a group of students mentored one another in the provision of patient care.

\section{DESCRIPTION OF PROJECT Environment}

The clinical teaching unit was created at a 336-bed acute care community hospital in Red Deer, Alberta, a city of 90000 people. The project took place on a 36-bed general medicine/stroke care unit. At the time of the project, pharmacists were well established on this unit, providing ward-based clinical services without drug distribution activities on weekdays. Pharmacists prioritized which patients would receive care, as the workload prohibited provision of full pharmaceutical care to all patients. The pharmacist preceptors had all achieved the Accredited Canadian Pharmacy Resident designation, and all had previous experience serving as preceptors for student pharmacists and/or residents.

The clinical teaching unit was initially designed to accommodate 12 final-year students, each for a 6-week experiential rotation, according to the usual structured program. However, because hospital rotations for the academic year were already set and because specific timelines were required by the external funding agency, a 6-student, 9-week rotation was created in consultation with the Faculty of Pharmacy and Pharmaceutical Sciences at the University of Alberta, Edmonton, Alberta. The clinical teaching unit was offered as a 9-credit elective course for students who had already completed the university's required experiential rotations, in place of elective course work. The 2 groups of students started at staggered times over the period January through April 2009, to ensure continuous student coverage on the unit. This approach also allowed more experienced students to mentor incoming students (Table 1). Students were given dedicated work space, computers, pagers, and pharmacotherapy references on the patient care unit.

\section{Orientation}

The first week after each group of students arrived was considered the orientation period. During this time, expectations of the students were outlined in relation to hospital policies, the patient care area, the health care team, direct patient care duties (including history-taking and a standardized approach to verbal presentation of patients), 
This single copy is for your personal, non-commercial use only.

For permission to reprint multiple copies or to order presentation-ready copies for distribution, contact CJHP at cjhpedit@cshp.ca

Table 1. Initial Schedule for Students and Preceptors in the Clinical Teaching Unit

\begin{tabular}{lccc} 
Group & Weeks 1-4 & Weeks 5-9 & Weeks 10-13 \\
\hline $\begin{array}{l}\text { A (3 students) } \\
\text { B (3 students)* }\end{array}$ & Started rotation & Completed rotation & NA \\
\hline NA = not applicable. & Started rotation & Completed rotation \\
*One student withdrew before starting the program, for personal reasons, leaving 2 students in the rotation.
\end{tabular}

journal club, and peer-assisted learning. As part of regular academic experiential rotations, students are required to complete a self-assessment at the start of each experiential rotation. In the clinical teaching unit, students discussed their self-assessments with the unit's pharmacy team during orientation, so that peers and preceptors alike could contribute to each student's growth over the rotation.

At the start of the rotation, students participated in an orientation on giving and receiving feedback. Each student's first patient history or assessment was witnessed by the preceptor and the other students, all of whom provided feedback to the student completing the task. In addition, the preceptor provided advice on the feedback that students gave to each other, to improve their feedback skills.

\section{Activities}

Once the orientation was complete, students individually provided pharmaceutical care to patients, similar to what happens in the traditional 1:1 preceptor-to-student model. Activities included assessment of patients and history-taking; review of patient records; creation, implementation, and follow-up of care plans, in conjunction with patients and the health care team; and documentation in the patient's medical record. Students interviewed patients, reviewed medical records, and created care plans without the direct involvement of the preceptor. However, the preceptor did review and approve the final plan created by the student and cosigned all chart documentation.

The students were not assigned a set number of patients for whom they had to provide care. The preceptor and student together determined when the student's workload could accommodate additional patient-related responsibilities, according to the acuity and complexity of the patients already assigned to the student. The patients assigned to students were from the preceptor's workload.

Daily clinical teaching unit rounds allowed students to present their patient care plans in a structured format to the unit's pharmacy team and to receive feedback from the group on their work. These rounds also provided an opportunity for students to discuss the rationale and clinical reasoning behind their actions. This was the only dedicated time allocated for discussion of patients by the preceptor and the students (Table 2 ), although the preceptor was available for such discussion at other times, if needed. However, students were encouraged to approach their peers for assistance before involving the preceptor. Students also participated in multidisciplinary bedside rounds for stroke patients with other members of the health care team. For the rest of the day, students provided direct patient care by enacting their care plans and providing drug information. They also participated in peer-assisted learning by reviewing answers to drug information questions or reviewing the chart notes or other work of their peers.

A journal club was created for the students in the clinical teaching unit, whereby each student was responsible for presenting one self-selected article during his or her rotation, preferably relevant to a patient under the student's care. The students also completed a learning log to reflect the educational process and the knowledge and skills they were gaining.

\section{Evaluation}

Students and preceptors provided formative feedback to each other throughout the course. Summative evaluation followed the usual practices of the University of Alberta. However, students were expected to complete their own evaluations and provide evidence of how various competencies had been met as a self-reflection exercise. The completed evaluation forms were reviewed by the preceptors, who also assigned a mark. Students were also required to provide a confidential assessment of the peer-assisted learning skills of their peers, to ensure that students were accountable for their contributions.?

\section{Peer-Assisted Learning}

The "same-year dyadic peer-assisted learning" system was used, whereby students at the same point in their pharmacy academic program facilitated the learning of their peers. ${ }^{4}$ Students cared for individually assigned patients and participated in peer-assisted learning by reviewing the pharmaceutical care plans, chart notes, and answers to drug information questions of their peers, before review of these materials by a preceptor. Furthermore, the students occasionally observed each other performing clinical activities (such as taking medication histories, presenting cases, and providing medication counselling). Students were encouraged to critically review the work of their peers, consider different perspectives, and use questioning, feedback, and constructive criticism to assist their colleagues. Presentations on various topics were also occasion- 
This single copy is for your personal, non-commercial use only.

For permission to reprint multiple copies or to order presentation-ready copies for distribution, contact CJHP at cjhpedit@cshp.ca

Table 2. Typical Daily Activities of Participants in the Clinical Teaching Unit (CTU)

\begin{tabular}{|c|c|c|}
\hline Time & Student Activities & Preceptor Activities \\
\hline $0800-0900$ & Preparation for multidisciplinary rounds & Preparation for multidisciplinary rounds \\
\hline 0900-0930 & \multicolumn{2}{|c|}{ Participate in multidisciplinary rounds (joint activity) } \\
\hline $0930-1300$ & $\begin{array}{l}\text { Patient care, peer discussion, answering } \\
\text { drug information questions }\end{array}$ & Non-student activities \\
\hline $1300-1530$ & \multicolumn{2}{|c|}{ CTU rounds (joint activity) } \\
\hline $1530-1615$ & \multicolumn{2}{|c|}{ Wrap-up (joint activity) } \\
\hline
\end{tabular}

ally required of the students, and students further along in their rotations assisted with orienting newer students to the patient care unit when they arrived.

\section{Preceptor Support}

Preceptors were encouraged to assign any type of patient to students, to reflect real-world practice. ${ }^{8}$ Assignments included full pharmaceutical care work-ups, as well as targeted problemsolving, such as therapeutic drug monitoring. Preceptors completed a hospital-based preceptor workshop and were given a manual outlining the objectives of the course and the expectations of both students and preceptors.

A second pharmacist was available on the clinical teaching unit as a contingency plan in the event that the proposed program was unsuccessful and it became necessary to reassign students to multiple preceptors. The second pharmacist was scheduled to assist with patient care unit duties that were urgent or beyond the scope of a teaching situation. Three pharmacists rotated preceptorship activities in 3-week blocks, according to the usual pharmacist schedule, although one pharmacist had sole responsibility for orientation of incoming students.

The main objective of this project was to increase the capacity of the hospital to train student pharmacists without compromising the educational experience or increasing the preceptor's workload. Other objectives included improving the teaching experience for preceptors and improving the level of patient care provided.

\section{Project Experience}

Program evaluation consisted of quantification of workload; surveys of students, preceptors, patients, and other health care professionals; and student and preceptor focus groups. Only workload and selected results from the preceptor and student surveys are discussed in this paper.

Preceptors were asked to track their overtime during the clinical teaching unit project and to indicate whether this overtime was "typical" of periods when they were serving as preceptors or was "new" because of the clinical teaching unit model. Additional workload analysis was based on the hospital's existing electronic system for measuring pharmacists' workload.
Preceptors and students documented patient care workload electronically on the basis of the numbers and types of drug-related issues identified, the acceptance status of each recommendation, and the anticipated patient outcome of each recommendation. The methods for extracting workload data have been published previously. ${ }^{9}$ The total numbers of drug-related issues and patient outcomes identified by both pharmacists and students during the project were compared with data captured by the workload measurement system for the same pharmacists without students during the same time period (January through April) in 2008.

All students and preceptors were invited to complete a survey to evaluate the program. Because this survey was considered to constitute program evaluation as part of quality assurance, ethics board approval was not sought. Students and preceptors completed the survey after their final evaluations were complete, and participation was voluntary.

The survey consisted of 2 questionnaires, one for preceptors and the other for students. The surveys were nearly identical, except for the types of demographic information requested. In addition, the wording of each questionnaire was slightly different to reflect whether the respondent was a student or a preceptor.

The surveys were paper-based, self-reported questionnaires consisting of 140 questions for students and 135 questions for preceptors. Most of the questions were based on a 5-point Likert scale, where 1 = strongly disagree (or other negative response) and $5=$ strongly agree (or other positive response), along with 8 open-ended questions. Questions covered evaluation of how well the course met the predefined learning objectives, comparisons between the clinical teaching unit model and the traditional model (with 1:1 ratio of students to preceptors), and general satisfaction with the course. Each survey was pretested by 2 hospital pharmacists with little knowledge of the project.

\section{RESULTS}

Six students volunteered to participate in the clinical teaching unit, but 1 student withdrew for personal reasons before starting the unit. Therefore, 5 students and 3 preceptors (including A.J.L.) participated in the clinical teaching unit between January and April 2009 (Table 3). All of the students 
Table 3. Demographic Characteristics of Participants

\begin{tabular}{lcc} 
Characteristic & Students* $^{*}$ & Preceptors \\
\hline Total number & 5 & 3 \\
Gender, no. of women & 4 & 3 \\
$\begin{array}{l}\text { Age (years) } \\
<25\end{array}$ & 3 & 0 \\
$25-29$ & 2 & 1 \\
$30-34$ & 0 & 2 \\
\hline
\end{tabular}

${ }^{*}$ Of the 5 students who completed the rotation.

\section{Table 4. Extent of Increase in Student Competencies with the Clinical Teaching Unit Relative to the Traditional Model}

\begin{tabular}{lcc} 
Competency Area & \multicolumn{2}{c}{ Group; Mean \pm SD } \\
\cline { 2 - 3 } & $\begin{array}{c}\text { Student } \\
\text { Responses* }\end{array}$ & $\begin{array}{c}\text { Preceptor } \\
\text { Responses* }\end{array}$ \\
\hline Confidence & $5.0 \pm 0.00$ & $5.0 \pm 0.00$ \\
Independence & $5.0 \pm 0.00$ & $5.0 \pm 0.00$ \\
Judgment skills & $4.8 \pm 0.45$ & $4.7 \pm 0.58$ \\
Time management skills & $4.8 \pm 0.45$ & $4.0 \pm 0.00$ \\
Responsibility & $4.8 \pm 0.45$ & $5.0 \pm 0.00$ \\
\hline
\end{tabular}

SD = standard deviation.

*Based on a 5-point Likert scale, where $1=$ not at all and $5=$ to a great extent.

and preceptors responded to the survey, for a response rate of $100 \%$. Preceptors documented $1350 \mathrm{~min}(22.5 \mathrm{~h})$ of overtime during the project, of which $600 \mathrm{~min}(10 \mathrm{~h})$ was considered "new" to the clinical teaching unit model. However, when asked if the new model "resulted in increased overtime and extra hours worked on the preceptor", both students and preceptors disagreed (mean 2.8, standard deviation [SD] 0.84, for students; mean 2.7, SD 0.58, for preceptors).

In 2008 , for the same period of the year but without students, the pharmacists who served as preceptors in this study identified 151 drug-related issues. During the clinical teaching unit project, the preceptors and students identified 768 drug-related issues, a 508\% increase. Also in 2008, the pharmacists proposed their interventions to achieve a total of 288 different patient outcomes, compared with 1511 targeted outcomes during the clinical teaching unit. Pharmacists initiated 2.7 interventions per day in 2008, whereas the team initiated 12.4 interventions per day during the clinical teaching unit. The acceptance rate for recommendations was similar in the 2 periods (rejection rate $3.9 \%$ during the clinical teaching unit project versus $2.9 \%$ for the period when staff were working without students).

When asked about their satisfaction with the overall program experience, all of the students reported that they were "very satisfied", and all of the preceptors were "satisfied" or "very satisfied".

Both students and preceptors also felt that students' confidence, independence, judgment, time-management skills, and responsibility increased with the clinical teaching unit model compared with the traditional model (Table 4). Students most commonly identified the focus on peer-assisted learning and the skills of the preceptors as the most common reasons for this improvement, whereas preceptors most commonly identified the focus on peer-assisted learning and the length of the rotation.

\section{DISCUSSION}

The clinical teaching unit project increased capacity for experiential rotations on a general medicine unit, an area where this type of training can be difficult to arrange. ${ }^{10}$ The incorporation of peer-assisted learning strongly contributed to the program's success. Both students and preceptors were satisfied with the clinical teaching unit model, and all felt that the students' skills increased to a greater extent with the clinical teaching unit than with the traditional model of experiential education. One potential reason for this difference may be the "zone of proximal development", whereby peers may be better able to teach complex tasks, such as patient assessment and the provision of pharmaceutical care, than preceptors, who may find the tasks routine. ${ }^{4}$ Additionally, peer-assisted learning conforms with various learning theories about the importance of social interaction to learning. ${ }^{11}$ In a previous systematic review, peer learning was found to be an effective educational strategy for experiential education among health science students, improving not only the students' knowledge base but also their skills and attitudes. ${ }^{5}$

The number of patient interventions increased dramatically relative to the workload of the pharmacists (i.e., preceptors) alone during the same period in the previous year, likely because more individuals were available to provide care to more patients. As a result, the students were a benefit in terms of their contributions to the hospital's patient care workload.

The American College of Clinical Pharmacy recently published a white paper on quality experiential education, ${ }^{1}$ advocating a 2:1 ratio of students to preceptor in most situations, with ratios as high as 4:1 being acceptable. In the clinical teaching unit described here, the ratio was as high as 5:1, with good success at achieving rotation outcomes. Preceptors were well supported to accommodate this number of students, and the reliance on peer-assisted learning gave the preceptors time to participate in non-student activities. In fact, we found a 2:1 ratio insufficient for this model (see Table 1: Group B, weeks 10-13), possibly because fewer individuals were available to contribute to discussion. Overtime was slightly greater with this model than with the traditional model of experiential education. However, the "new" overtime of 10 recorded hours was small in relation to the total 504-h (13week) duration of the project. Furthermore, neither preceptors nor students perceived an increase in overtime or workload for the preceptors, as indicated by their survey responses. This 
difference might be attributable to the dates when overtime was recorded. For example, preceptors may have put in more overtime while getting used to the model, with overtime requirements decreasing over the course of the project.

This project had some limitations. Both students and preceptors were responding to a survey distributed by the host hospital, so there may have been a tendency to provide more positive responses. This response bias was minimized by ensuring that respondents did not have to submit completed surveys until after the final rotation evaluations were complete. In addition, the surveys were anonymous, and participants submitted completed surveys to an administrative assistant instead of to the preceptor or a manager. The student participants had all previously completed the mandatory rotations required by the University of Alberta. Therefore, those who volunteered may have had a higher aptitude for hospital practice. However, the students' previous experiences and associated skill sets were variable. Future plans for the clinical teaching unit include converting it from an elective to a mandatory experiential hospital rotation. Other plans include eliminating the second pharmacist who was available on the unit and possibly expanding the project to other areas of the hospital.

\section{CONCLUSIONS}

A clinical teaching unit for student pharmacists can increase placement capacity for experiential training without negatively affecting the learning experience of students or the workload of preceptors. The elements of peer-assisted learning, preceptor support, and a structured work environment assisted in ensuring that the rotation was a positive learning experience. In particular, students in our clinical teaching unit contributed beneficially to patient care workload.

\section{References}

1. American College of Clinical Pharmacy, Haase KK, Smythe MA, Orlando PL, Resman-Targoff BH, Smith LS. Ensuring quality experiential education. Pharmacotherapy 2008;28(12):1548-1551.

2. Management Committee. Moving forward: pharmacy human resources for the future. Final report. Ottawa (ON): Canadian Pharmacists Association; 2008 [cited 25 Nov 2011]. Available: http://blueprintforpharmacy.ca/ docs/default-document-library/2011/04/19/Moving\%20Forward\% 20Final\%20Report.pdf?Status=Master

3. Topping KJ. The effectiveness of peer tutoring in further and higher education: a typology and review of the literature. Higher Educ 1996; 32:321-345.

4. Ross MT, Cameron HS. Peer assisted learning: a planning and implementation framework: AMEE Guide no. 30. Med Teach 2007;29(6):527-545.
5. Secomb J. A systematic review of peer teaching and learning in clinical education. J Clin Nurs 2008;17(6):703-716.

6. Moore A, Morris J, Crouch V, Martine M. Evaluation of physiotherapy clinical educational models: comparing 1:1, 2:1 and 3:1 placements. Physiotherapy 2003;89:489-501.

7. Levine RE. Evaluation in team-based learning. In: Michaelsen LK, Parmelee DX, McMahon KK, Levine RE, editors. Team-based learning for health professions education. Sterling (VA): Stylus Publishing, LLC; 2008. p. 103-116.

8. Anderson C. Academic and institutional capacity: a global issue. Am J Pharm Educ 2008;72(5):114-115.

9. Lindblad AJ, Alleyne A, Howorko J. Development and initial evaluation of a software-based clinical workload measurement system for pharmacists. Can J Hosp Pharm 2007;60(5):295-301.

10. Capacity of hospitals to partner with academia to meet experiential education requirements for pharmacy students. Am J Health Syst Pharm 2008;65(1):e53-e71.

11. Baldry Currens J, Bithell CP. The 2:1 clinical placement model: perceptions of clinical educators and students. Physiotherapy 2003;89:204-218.

Adrienne J Lindblad, PharmD, is with Pharmacy Services, Red Deer Regional Hospital Centre, Alberta Health Services, Red Deer, Alberta.

Jason M Howorko, BSP, is with Pharmacy Services, Red Deer Regional Hospital Centre, Alberta Health Services, Red Deer, Alberta.

Richard P Cashin, PharmD, is with Pharmacy Services, Red Deer Regional Hospital Centre, Alberta Health Services, Red Deer, Alberta.

Cornelius J Ehlers, MA, was (at the time this article was prepared) with Knowledge Management, Red Deer Regional Hospital Centre, Alberta Health Services, Red Deer, Alberta.

Cheryl E Cox, MBA, is with the Faculty of Pharmacy and Pharmaceutical Sciences, University of Alberta, Edmonton, Alberta.

\section{Address correspondence to:}

Adrienne J Lindblad

Pharmacy Services

Red Deer Regional Hospital Centre

Alberta Health Services

3942-50A Avenue

Red Deer AB T4N 4E7

e-mail: adrienne.lindblad@albertahealthservices.ca

\section{Acknowledgements}

We are extremely grateful to our students; to our preceptors, Erin Cashin and Carmen Leung; and to Joanne Angelstad and Alison Alleyne for their assistance in program development.

Funding for this study was provided by Alberta Health and Wellness Health Workforce Action Plan-Building and Enhancing Clinical Capacity Fund.

The design and structure of the clinical teaching unit was presented in part as a poster at the Association of Faculties of Pharmacy of Canada annual conference in Halifax, Nova Scotia, on June 5, 2009. Preliminary results were presented in part as a poster at the Canadian Society of Hospital Pharmacists Professional Practice Conference in Toronto, Ontario, on February 1, 2010. 